\title{
Satellite Monitoring System of Subalpine Lakes with Open Source Software: the Case of SIMILE Project
}

\author{
Giulia LUCIANI $^{1 *}$, Mariano BRESCIANI ${ }^{2}$, Carlo Andrea BIRAGHI ${ }^{1}$, \\ Nicola GHIRARDI ${ }^{2}$, Daniela CARRION ${ }^{1}$, Michela ROGORA ${ }^{3}$, \\ Maria Antonia BROVELLI ${ }^{1,2}$ \\ ${ }^{1}$ Politecnico di Milano - Lecco Campus, Department of Civil and Environmental Engineering, \\ Via Gaetano Previati, 1/c, 23900 Lecco, Italy \\ ${ }^{2}$ Istituto per il Rilevamento Elettromagnetico dell'Ambiente, CNR-IREA, \\ Via Bassini 15, 20133 Milano, Italy \\ ${ }^{3}$ Istituto di Ricerca sulle Acque, CNR-IRSA, Largo Tonolli 5028922 -Verbania Pallanza, Italy \\ 1 g giulia.luciani, carloandrea.biraghi, daniela.carrion, \\ maria.brovelli\} apolimi.it \\ 2 (bresciani.m, ghirardi.n) @irea.cnr.it \\ 3 (michela.rogoradirsa.cnr.it)
}

\begin{abstract}
SIMILE Project has the aim of supporting the definition of management policies and the operational decisions for the insubric Lakes through an innovative information system based on data from an integrated monitoring system, consisting of remote sensing of water quality parameters of the lakes with latest generation satellite images, buoys equipped with sensors for the continuous detection of limnological and meteorological parameters within the lakes and in the use of additional data on water quality that will be collected through citizen science. Maggiore, Lugano and Como are the lakes involved in the project. This paper presents the satellite monitoring system implemented for the project, based on open data and GIS tools, together with the results obtained in the first 18 months of activities.
\end{abstract}

Keywords. Simile Project, remote sensing, water quality, lakes, open source tools

\section{Introduction}

SIMILE (Information System for the Integrated Monitoring of Insubric Lakes and their Ecosystems) is an INTERREG Italy-Switzerland Project launched in 2019 (Brovelli et al., 2019), with the aim of supporting the management policies and operational decisions for the Subalpine Maggiore, Lugano and Como lakes. These lakes are key elements for the economy of the surroundings as their waters are extensively used for civil and industrial purposes. These lakes cross the borders of the two states and therefore a joint coordinated action is necessary to guarantee the preservation of their quality. The

* Corresponding author 
innovation introduced by the project consists of the realization of an integrated monitoring system involving remote sensing with the latest generations satellite multispectral images, buoys equipped with sensors for the continuous detection of limnologic and meteorological parameters, and the use of additional data collected through citizen science, which allows integrating and enhancing the traditional water sampling procedures with cost-effective methods.

This paper presents the satellite monitoring system implemented for the project and the results obtained in the first 18 months of activities. Remote sensing techniques have been implemented for decades as an integrative tool for monitoring Water Quality Parameters (WQPs). Satellite optical remote sensing has been widely used to produce WQPs maps at relatively low costs, at various spatial and temporal resolution. In the last decade there was a notable increase in inland water studies and operational applications based on optical satellite images (Topp et al., 2020; Bresciani et al., 2020; Tyler et al., 2016) as a consequence of improvements in sensors resolution which make remote sensing a powerful instrument to obtain synoptic views of water bodies to monitor their quality status.

The parameters that can be mapped are mainly the optically active WQP: chlorophyll-a concentration (CHL-a) and total suspended solids (TSM), as well as surface temperature and the presence of various types of anomalies. These indicator parameters are the ones monitored in SIMILE, as they are the main factors that can influence the quality of the water bodies.

The maps obtained with the satellite monitoring system will enhance the capability of traditional sampling campaigns, extending the observation methodology of water quality from punctual to synoptic and high-frequency views.

All the images and tools used for the satellite monitoring in SIMILE project are free of charge. The images are downloaded from the spatial agencies web portals and processed with open source algorithms to produce the maps of WQPs. The maps will feed into a dedicated geoportal, which is still under development, where local agencies of environmental protection and interested users can visualize and download the products.

The processing of satellite images here presented, based on open data and tools, will be shared with public administrations' officers of both countries through a free training programme to continue the monitoring with the use of free and open software after the project completion.

\section{Study Area}

The lakes of the Subalpine Region (Fig.1), Maggiore (surface area $212.5 \mathrm{~km}^{2}$ ), Lugano (surface area $48.7 \mathrm{~km}^{2}$ ) and Como (surface area $145.5 \mathrm{~km}^{2}$ ), are classified as deepoligomictic, with maximum depths of 372, 288 and 418 meters, respectively. These water bodies contribute about $40 \%$ to the discharge of the River Po, the largest Italian river, and constitute more than $80 \%$ of the surface water resources in Italy (Salmaso et al., 2012).

They are narrow, elongated and delimited laterally by steep sides. Owing to climatic conditions and the depth of the lakes the mixing historically only occurred every 7 years, typically down to a depth of $200 \mathrm{~m}$ during cold and windy winters. Lake Maggiore and Lake Como are included in the LTER network in the Macrosite "IT08 Subalpine Lakes". 

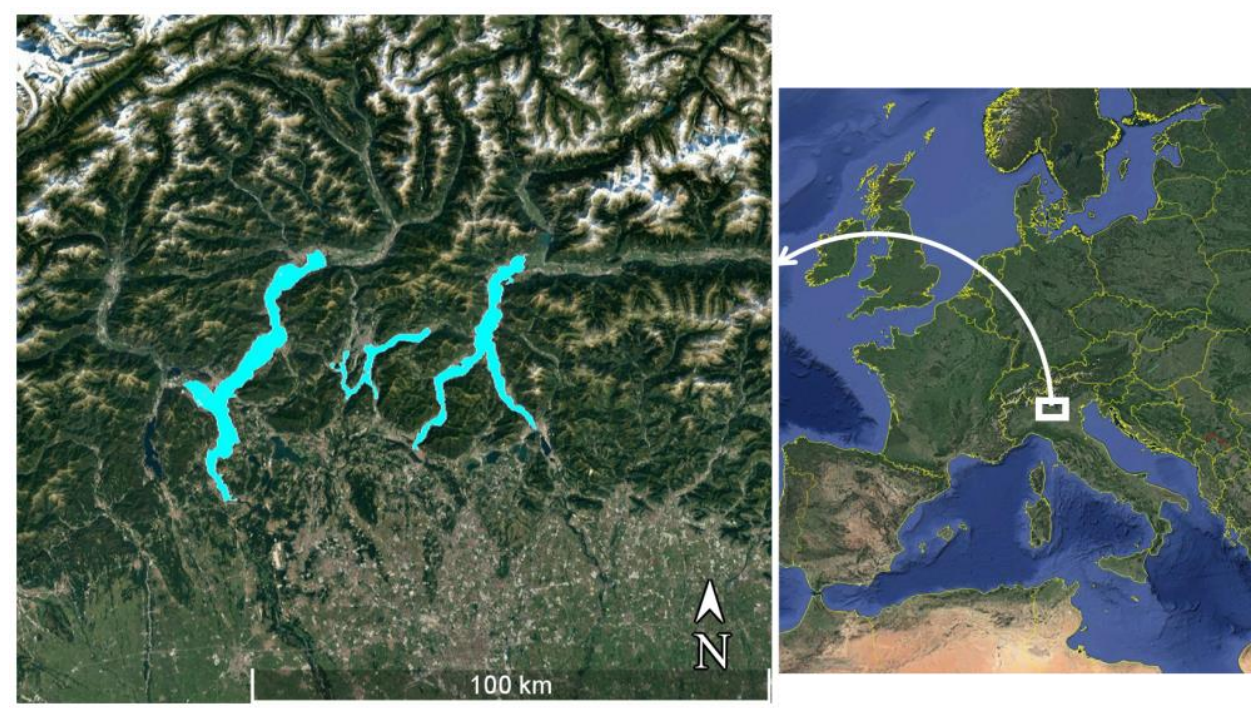

Fig.1. Location of the three sub-alpine lakes monitored in SIMILE project, from the left to the right: Maggiore, Lugano and Como.

\section{Materials and methods}

In SIMILE the images acquired by the sensors OLCI (Ocean and Land Colour Instrument) on board Sentinel 3 European Space Agency's (ESA's) satellites (spatial resolution $300 \mathrm{~m}$ ), were chosen to produce high frequency maps of WQPs CHL-a and TSM concentrations, due to their daily revisit time. The images are downloaded from ESA's web portal (https://scihub. copernicus.eu/). OLCI acquires data in 21 spectral bands in the VIS-NIR range, specifically suited to the assessment of aquatic ecosystems. The medium spatial resolution is balanced by the high frequency of acquisition of the OLCI images, which, net of cloudy or noisy images, allows the detection of phenomena that occur at short timespans (less than two weeks).

In addition, when anomalies or unexpected concentrations of the WQPs are detected at the water surface, a more detailed spatial information is gathered using the higher spatial resolution of the MSI (Multispectral Instrument) sensors on board ESA's Sentinel 2 satellites (spatial resolution 10-20-60 m). MSI sensors acquire less frequently, with respect to OLCI, about one image per week at our latitudes depending on the tile, and their bands and signal are not specifically designed for aquatic studies, but their images adequately corrected for atmospheric disturbs and processed with appropriate bio-optical models can handle the complexity of inland waters in retrieving the WQPs, as successfully demonstrated in Cazzaniga et al. (2019) and Bresciani et al. (2018) for subalpine lakes and in Dörnhöfer et al. (2016) for oligotrophic lakes. The images acquired by the sensor TIRS (Thermal Infrared Sensor), on board the National Aeronautics and Space Administration (NASA) Landsat-8 satellite $(100 \mathrm{~m})$ downloaded from the USGS portal (https://earthexplorer.usgs.gov/) complement the dataset for monitoring the temporal evolution of the lakes surface temperature. 
The processing of the OLCI images to obtain maps of CHL-a and TSM was carried out with ESA's SentiNel Application Platform (SNAP) https://step.esa.int/main/toolboxes/snap/(Zuhlke et al., 2015). The open source code of SNAP is distributed by ESA (https://github.com/senbox-org). The radiometric and atmospheric correction of the images and the retrieval of the WQPs, was performed with the Case 2 Regional Coast Colour (C2RCC) (Brockmann et al., 2016), an open source processor based on a neural network, implemented as a plugin in SNAP (the source code of $\mathrm{C} 2 \mathrm{RCC}$ is available here https://github.com/senbox-org/ s3tbx/blob/master/s3tbx-c2rcc/src/main/java/org/esa/s3tbx/ c2rcc/olci/C2rCCOlciAlgorithm.java. The C2RCC is a widely used water quality processor for complex and inland waters and it has been tested in various studies (e.g. Kyryliuk and Kratzer, 2019; Soomets et al., 2020).

As the processor allows to modify the default setting of some processing parameters to better adapt to local regional characteristics, for each image the C2RCC was parameterized with temperature data at the time of the sensor's acquisition, manually downloaded from the websites of local regional environmental protection agencies, and they were adopted site-specific coefficient for the inherent optical properties (IOP) of the lakes. These coefficients were defined with validated methodologies from laboratory data acquired in different field campaign in previous studies of remote sensing in Subalpine Lakes (Giardino et al., 2014; Bresciani et al., 2018). During this phase of the project all the images from OLCI Sentinel-3 and TIRS Landsat 8 were selected for download individually and processed manually in SNAP. Regarding OLCI, WQP products were masked using the flags produced with the $\mathrm{C} 2 \mathrm{RCC}$, where the neural nets of the processor detected possible cloud risk and anomalies in the water spectra, such as those due to adjacency effects along the borders of the lakes. To this aim the C2RCC flags that were evaluated as the most appropriate were the Cloud_risk, Rtosa_OOS, Rtosa_OOR, Rhow_OOS and Rhow_OOR, the latest indicating the input spectrum to the atmospheric correction neural net or the input spectrum to derive the WQPs were not within the training range of the respective neural nets or outside the range of the expected results. For some images showing in some cases high WQP concentration values in correspondence with thin clouds and areas affected by glints, the noise masking proposed by $\mathrm{C} 2 \mathrm{RCC}$ was not sufficient and an additional mask was used, defined based on the identification of a threshold value in the NIR band $(867 \mathrm{~nm})$.

To check the accuracy of the atmospheric correction performed by $\mathrm{C} 2 \mathrm{RCC}$, from which the WQPs are subsequently retrieved by the processor, the atmospherically corrected reflectances were compared with available in situ data, measured between August 2017 and July 2019 in the lakes with a WISP-3 spectroradiometer in the range of 400-800 nm, according to the Seawifs protocol. To test the final products of the sitespecific parametrization implemented for the Subalpine region, the WQPs retrieved by C2RCC were compared with the available in situ data, consisting of 17 laboratory measures of CHL-a concentration, carried out on water samples collected at different positions in the lakes between 2017 and 2020 by the local environment protection agencies and partners of the SIMLE project. In situ data for CHL-a were compared with the averaged output of $\mathrm{C} 2 \mathrm{RCC}$ extracted from $3 \times 3$ pixels regions centred at the sampling point location.

MSI images were atmospherically corrected with the Second Simulation of a Satellite Signal in the Solar Spectrum, Vector (6Sv) code (Vermote et al., 1997) 
(http://6s.Itdri.org/pages/run6SV.html). The cloud masking was performed in SNAP based on a threshold on near-infrared bands, as 6Sv doesn't masks clouds. The cyanobacteria blooms were detected on atmospherically corrected MSI images based on phycoerythrin's pigments, which influence the water signature in a region near $590 \mathrm{~nm}$ wavelength. We used a band ratio B4 $(665 \mathrm{~nm}) / \mathrm{B} 3(560 \mathrm{~nm})$ with a threshold value of 1 to identify pixels influenced by the presence of cyanobacteria in the surface layer. The images were also processed with the bio-optical model BOMBERBio-Optical Model Based tool for Estimating water quality and bottom properties from Remote sensing images (Giardino et al., 2012) parametrized with the specific IOP of subalpine lakes, to the aim of foams detection.

The images acquired by the TIRS sensor were radiometrically calibrated and the surface temperature of the lakes was obtained with the Barsi method (Barsi, 2015). This requires atmospheric auxiliary data input from external USGS data sources, that have to be downloaded from the website (https://atmcorr.gsfC.nasa.gov/). These are used to derive the BOA (Bottom Of Atmosphere) radiances with the radiative transfer equation, and then to obtain the surface temperature of the water from the inversion of the Planck equation, approximated with specific constants known for the Landsat 8. The algorithm for the atmospheric correction is described clearly in the cited bibliographic reference and can be implemented with the SNAP Band Math module. Also in this case, for some images the Landsat cloud masks were not sufficient to exclude pixels affected by thin clouds or cloud shadows, requiring additional masking in SNAP based on user selected thresholds on NIR bands.

Both the procedure of producing CHL-a and TSM maps from OLCI images with C2RCC, and lake surface temperature maps from Landsat 8 with Barsi method were performed with SNAP. This allows to produce the maps in some minutes as soon as the images are available for download. During the first phase the maps are produced by the partners of the project to feed the geoportal, in the second phase, the maps are provided to lake management.

Investigations on the presence of anomalies were carried out if high concentrations were detected in OLCI maps or with the other SIMILE's monitoring tools, such as the buoys. This required the selection and download of the available Sentinel-2 images, preprocessing and cloud masking in SNAP, atmospheric correction with $6 \mathrm{~S}$ code and processing of the images with BOMBER, which has to be carried out by expert users of remote sensing.

\section{Results and discussion}

The atmospherically corrected reflectances obtained with C2RCC from the OLCI images were found to be in good agreement, in terms of shape and magnitude (Fig. 2a), with available in situ data measured between August 2017 and July 2019. The WQPs retrieved by $\mathrm{C} 2 \mathrm{RCC}$ were also consistent with laboratory measurements of in situ collected water samples, as demonstrated by a coefficient of determination $\mathrm{R}^{2}$ of 0.72 , calculated for the 17 points dataset (Fig. 2b). 

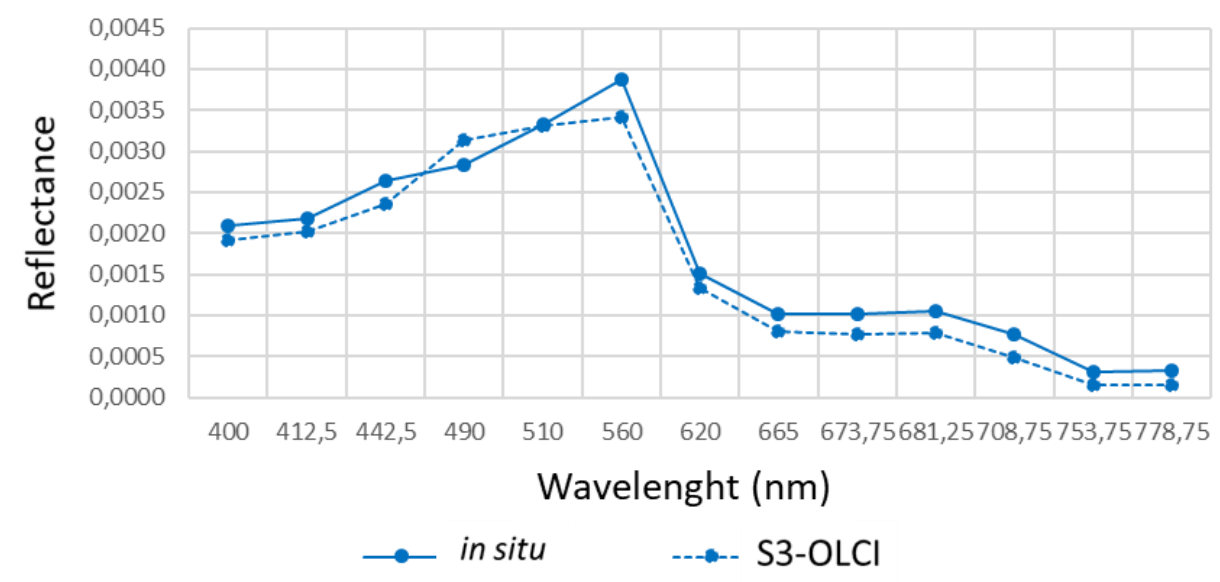

a)

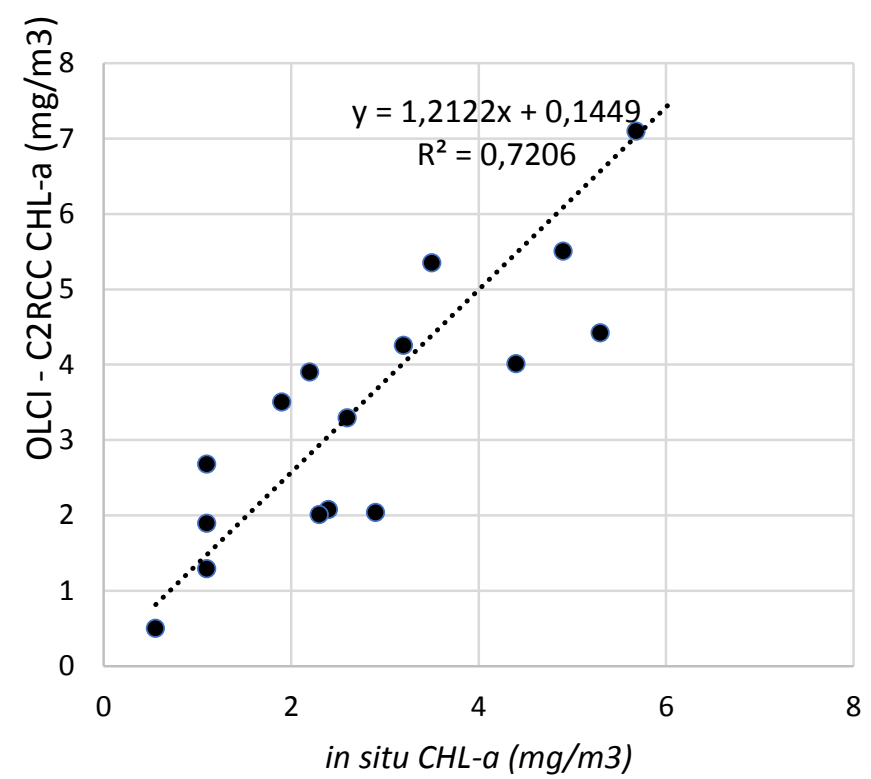

b)

Fig.2 a) Comparison of water reflectance spectra obtained in situ (WISP) and measured by Sentinel-3 OLCI atmospherically corrected with C2RCC; b) Scatterplot of in situ measured CHL-a $\left(\mathrm{mg} / \mathrm{m}^{3}\right)$ vs. satellite derived CHL-a $\left(\mathrm{mg} / \mathrm{m}^{3}\right)$

All the images which were not affected by clouds for at least half of the lake were processed with C2RCC. Some of these were excluded from the final maps dataset due to the presence of radiometric disturbances or because they were masked out by C2RCC. Net of all this, during the period between January 2019 and mid-August 2020135 WQPs 
maps retrieved from OLCI. The maps were produced on average every 4 days, with higher frequencies in the spring and summer months (every 2 days) and lower in the autumn and winter months, as it can be seen in Fig. 3.

Examples of the maps are presented in Fig.4. This remotely sensed dataset can describe spatial and temporal variability of WQP concentration within the lakes, as shown for example by maps of total suspended solids concentrations, which indicate the presence of higher concentrations near the major tributaries of Como Lake (Adda river) during several days in May 2019. In this event the concentrations reached the maximum value of $4 \mathrm{~g} / \mathrm{m}^{3}$, while the average annual concentrations of the lake are lower than $1 \mathrm{~g} / \mathrm{m}^{3}$.

Overall, the data obtained are consistent with data obtained in monitoring campaigns of previous years, confirming the oligo-mesotrophic conditions of the lakes, highlighting local differences. The spring months of May exhibited the lowest CHL-a concentrations in both years. Chlorophyll concentrations showed maximum values in the Southern basin of Lake Lugano in which the surface concentrations exceed $10 \mathrm{mg} / \mathrm{m}^{3}$ in the spring of 2019 and 2020. For Lake Maggiore the highest values were recorded in late autumn and winter, while in Como Lake the worst conditions occurred in late summer and autumn.

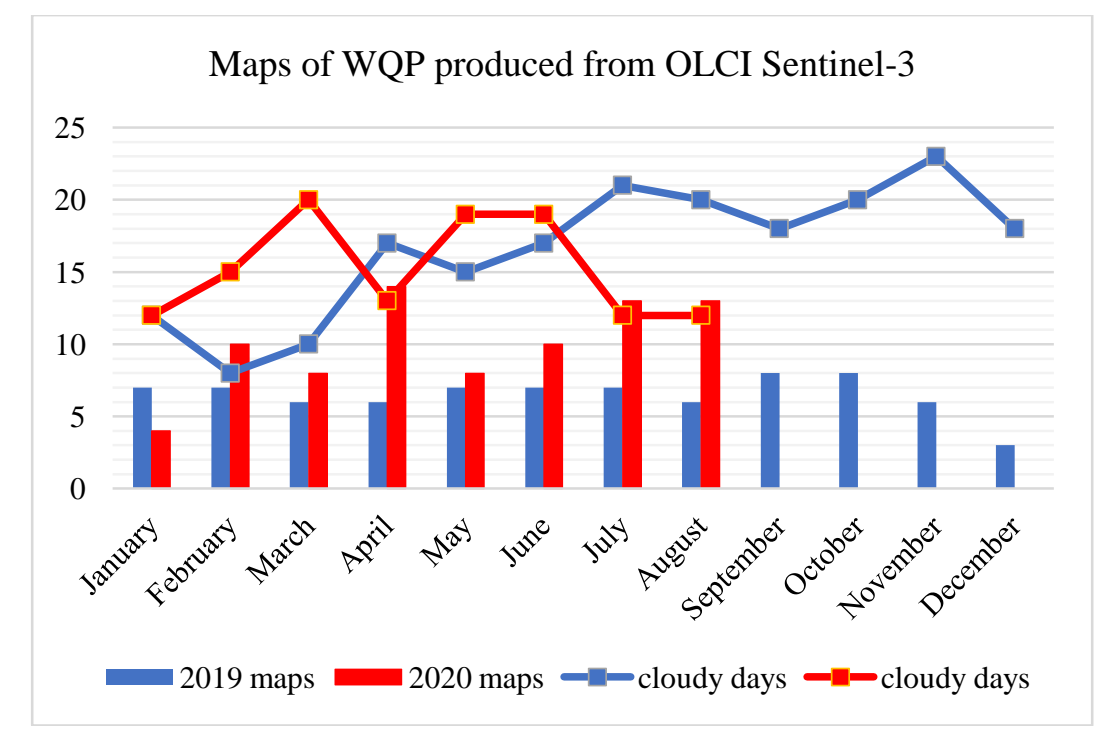

Fig. 3. Number of maps of WQP produced from OLCI Sentinel-3 during the first months of the project

In regard to the detection of episodes that occurred at short timespans, during two weeks in September 2019 where OLCI processing exhibited anomalous concentrations in Maggiore Lake, the processing of the available MSI Sentinel-2 images revealed the presence of foams. In that case, the bio-optical model BOMBER was run with specific absorption and backscattering properties on Lake Maggiore for the whole lake area, allowing to distinguish the pixels for which BOMBER's procedure had an acceptable 
optimization error in retrieving WQP from those with high optimization errors, where thus foam signals were expected to be detectable. The higher spatial resolution of the MSI images allowed the delineation of the area covered by the foams, which was about 25 hectares on 09 September 2019. An episode of cyanobacterial blooms was detected in Lake Lugano between the end of December 2019 and the first two weeks of January 2020 (the surface cyanobacteria accumulation covered 2.5 hectares on 02 January 2020), while an episode of algal blooms recorded at the end of March 2020 in Maggiore Lake was not attributed to cyanobacteria.

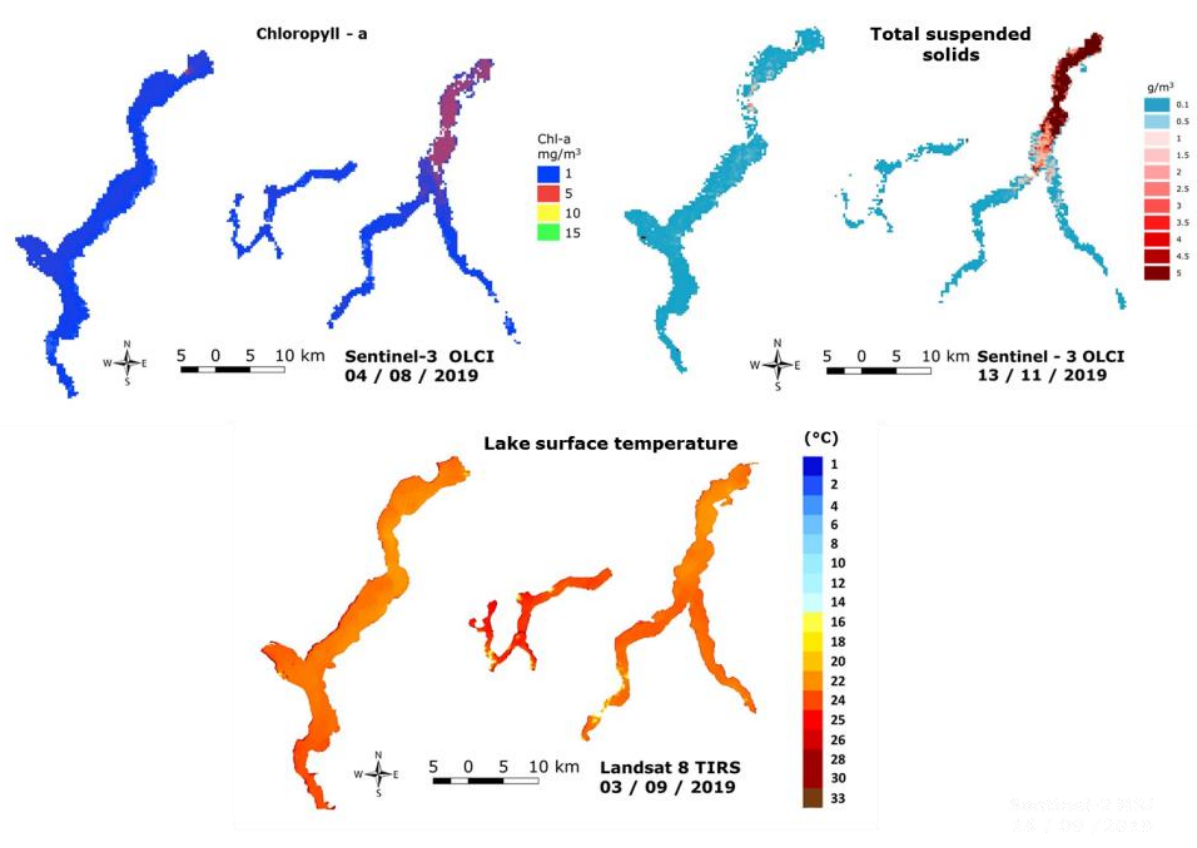

Fig.4. Water quality maps

The 35 surface temperature maps obtained with Landsat- 8 made it possible to evaluate differences of up to two or three degrees between different areas of the lakes, i.e. between the lakes centres and coastal zones where the inlet of the rivers are located, whose waters are generally colder in the spring months, allowing to define the fluvial inlet areas in the lake waters.

\section{Conclusions}

The high frequency, mid-high spatial resolution monitoring system implemented in SIMILE Project offers a more detailed spatial and temporal information with respect to other ready-to-use products. The synoptic and high frequency view offered by the remote sensing monitoring system allowed the detection of the overall trends of water quality parameters concentrations and the extension of areas affected by algal blooms and/or cyanobacterial blooms in the three lakes involved in the project during the first 
months of the project. An analysis of the frequency and persistence of the blooms in different sub-regions of the lakes is being undertaken with QGIS to give possible insights which can inform and optimize management decision regarding field sampling strategies. The synergy of the operation of satellite monitoring system with the buoys, that will be soon operative, in punctual continuous monitoring of WQP along the coast of the lakes, will guarantee a comprehensive view of waters quality status.

The free availability of the new generation satellite images and open source tools used for their processing, together with the free training programme offered by SIMILE Project to public administrations' officers and technicians of both countries, will facilitate the prosecution of the satellite monitoring activity after the project completion.

\section{Acknowledgements}

This work was supported by SIMILE, an Interreg Italian-Swiss project funded by the European Regional Development Fund (ERDF) ID: 523544. We want to thank the other partners of the project and we also want to thank CNR-IREA for the collaboration related to satellite monitoring and the Regional Agency for Environmental Protection (ARPA) of the Lombardy Region for the cooperation in lake monitoring.

\section{References}

Barsi, J. A., Schott, J. R., Palluconi, F. D., Hook, S. J. (2005). Validation of a web-based atmospheric correction tool for single thermal band instruments, in Earth Observing Systems $X$, Vol. 5882, p. 58820E. International Society for Optics and Photonics.

Bresciani, M., Pinardi, M., Free, G., Luciani, G., Ghebrehiwot, S., Laanen, M., Peters, S., Della Bella, V., Padula, R., Giardino, C. (2020). The use of multisource optical sensors to study phytoplankton spatio-temporal variation in a Shallow Turbid Lake, Water, 12(1), p.284.

Bresciani, M., Cazzaniga, I., Austoni, M., Sforzi, T., Buzzi, F., Morabito, G., Giardino, C. (2018). Mapping phytoplankton blooms in deep subalpine lakes from Sentinel-2A and Landsat8, Hydrobiologia, 824(1), pp.197-214.

Brockmann C., Doerffer R., Peters M., Kerstin S., Embacher S., Ruescas A. (2016). Evolution of the C2RCC neural network for Sentinel 2 and 3 for the retrieval of ocean colour products in normal and extreme optically complex waters, Living Planet Symposium, Vol. 740, p. 54.

Brovelli, M. A., Cannata, M., Rogora, M. (2019). SIMILE, A Geospatial Enabler of the Monitoring of Sustainable Development Goal 6 (Ensure Availability and Sustainability of Water for All), Int. Arch. Photogramm. Remote Sens. Spatial Inf. Sci., XLII-4/W20, 3-10, https://doi.org/10.5194/isprs-archives-XLII-4-W20-3-2019

Cazzaniga, I., Bresciani, M., Colombo, R., Della Bella, V., Padula, R., Giardino, C. (2019). A comparison of Sentinel-3-OLCI and Sentinel-2-MSI-derived Chlorophyll-a maps for two large Italian lakes, Remote Sensing Letters, 10(10), pp.978-987.

Dörnhöfer, K., Oppelt, N. (2016). Remote sensing for lake research and monitoring-Recent advances, Ecological Indicators, 64, p.105-122.

Giardino, C., Bresciani, M., Stroppiana, D., Oggioni, A., Morabito, G. (2014). Optical remote sensing of lakes: an overview on Lake Maggiore, J. Limnol, 73(s1), pp.201-214.

Kyryliuk, D., Kratzer, S. (2019). Evaluation of Sentinel-3A OLCI products derived using the Case-2 Regional CoastColour processor over the Baltic Sea, Sensors, 19(16), p.3609.

Salmaso, N., Buzzi, F., Garibaldi, L., Morabito, G., Simona, M. (2012). Effects of nutrient availability and temperature on phytoplankton development: a case study from large lakes south of the Alps, Aquatic Sciences, 74(3), pp.555-570. 
Soomets, T., Uudeberg, K., Jakovels, D., Brauns, A., Zagars, M., Kutser, T. (2020). Validation and Comparison of Water Quality Products in Baltic Lakes Using Sentinel-2 MSI and Sentinel-3 OLCI Data, Sensors, 20(3), p.742.

Tyler, A.N., Hunter, P.D., Spyrakos, E., Groom, S., Constantinescu, A.M., Kitchen, J. (2016). Developments in Earth observation for the assessment and monitoring of inland, transitional, coastal and shelf-sea waters, Sci Total Environ, 572, 1307-1321.

Topp, S. N., Pavelsky, T. M., Jensen, D., Simard, M., Ross, M. R. (2020). Research trends in the use of remote sensing for inland water quality science: Moving towards multidisciplinary applications, Water, 12(1), p.169.

Vermote, E. F., Tanré, D., Deuze, J. L., Herman, M., Morcette, J. J. (1997). Second simulation of the satellite signal in the solar spectrum, 6S: An overview, IEEE transactions on geoscience and remote sensing, 35(3), 675-686.

Zuhlke, M., Fomferra, N., Brockmann, C., Peters, M., Veci, L., Malik, J., Regner, P. (2015). SNAP (sentinel application platform) and the ESA sentinel 3 toolbox, Sentinel-3 for Science Workshop, 734.

Received August 31, 2020, revised February 19, 2021, accepted February 24, 2021 